\title{
First record of Erasmoneura vulnerata Fitch, 1851 (Hemiptera, Cicadellidae, Typhlocybinae) in Switzerland
}

\author{
Attilio Rizzoli ${ }^{1}$, Riccardo Battelli ${ }^{2}$, Marco Conedera $^{1}$, Mauro Jermini $^{3}$ \\ 1 Swiss Federal Institute for Forest, Snow and Landscape Research WSL - Campus di ricerca, A Ramél 18, CH-6593 Cadenazzo, Switzerland \\ 2 Plant protection service of Canton Ticino - Viale Stefano Franscini 17, CH-6501 Bellinzona, Switzerland \\ 3 Agroscope-Campus di ricerca, A Ramél 18, CH-6593 Cadenazzo, Switzerland \\ http://zoobank.org/A728CDAC-FF4E-4C16-8F2C-5A4787A73051
}

Corresponding author: Attilio Rizzoli (attilio.rizzoli@wsl.ch)

Academic editor: Roland Mühlethaler • Received 6 May 2020 • Accepted 30 June 2020 • Published 14 July 2020

\begin{abstract}
The first record of Erasmoneura vulnerata Fitch, 1851 in Switzerland is reported. Specimens were collected in 2019 using yellow sticky traps during a Scaphoideus titanus monitoring campaign in vineyards in Ticino (Southern Switzerland). E. vulnerata is a grapevine pest that has recently been introduced to Europe, whose phytophagy causes detrimental damage to grapevine leaves. Its occurrence in this area has likely been favored by the ongoing suspension of insecticide treatments for the control of the $S$. titanus population, the vector agent of the "Flavescence dorée" phytoplasma in grapevines.
\end{abstract}

\section{Key Words}

Erythroneura, grapevine pest, leafhopper, Neozoa

\section{Introduction}

Erasmoneura vulnerata Fitch, 1851 (syn. Erythroneura vulnerata Fitch, 1851) (Hemiptera, Cicadellidae, Typhlocybinae) is a Nearctic leafhopper that colonizes North-American grape species (Vitis spp.) as well as various cultivars of Vitis vinifera L. (Dietrich and Dmitriev 2006). It may also use Parthenocissus quinquefolia L. Planch. as a secondary host (Dmitriev et al. 2020). In its native range, E. vulnerata was first described as a significant grapevine pest by Robinson (1926) and Beamer (1946) and is now considered to be a prominent species among the many leafhoppers associated with grapevines (Martinson and Denney 1995; Paxton and Thorvilson 1996). Vineyards in Colorado and Texas, for example, are attacked by E. vulnerata in association with Erythroneura coloradensis Gillette, 1892 and Erythroneura ziczac Walsh, 1862 (Zimmerman et al. 1996).

E. vulnerata has recently been introduced to Europe, where it was first recorded in Northeastern Italy (Veneto region) in 2004, followed by subsequent findings in
Friuli-Venezia Giulia (Duso et al. 2005). Later, additional specimens of the leafhopper were trapped in other North-Italian regions such as Emilia-Romagna and Trentino-Alto Adige on vines of Vitis labrusca L. and on French hybrids where no phytosanitary measures were applied, and on Parthenocissus spp. (Duso et al. 2008).

E. vulnerata has a very low occurrence rate in the surveyed Italian vineyards treated with insecticides against Scaphoideus titanus Ball, 1932, the main vector of Candidatus Phytoplasma vitis responsible for the quarantine disease "Flavescence dorée" (Chuche and Thiéry 2014; Duso et al. 2019; OSalV-DEFR-DATEC 2019). This led Duso et al. (2019) to categorize this species as a secondary grapevine pest in North-Italian commercial vineyards, where insecticides are commonly used for the mandatory control of $S$. titanus.

In 2010, E. vulnerata specimens were accidentally detected on Cercis siliquastrum L. in Slovenia, close to the Italian border (Seljak 2011). Subsequent surveys confirmed the presence of a few specimens of $E$. vulnerata on Vitis spp. also, mainly on Vitis labrusca which were most 
likely not treated with insecticides. Seljak (2011) additionally reported that the Judas tree is a viable and attractive host for adult specimens, but did not elaborate further on the introduction of E. vulnerata to Slovenia other than the possible effect of the proximity to the Italian border.

Here, we report the first record of E. vulnerata in vineyards in Ticino (Southern Switzerland) which occurred in 2019 and which was already expected by Mühlethaler et al. (2016). The finding took place during a monitoring campaign of the vectoring agent of the grapevine "Flavescence dorée" phytoplasma, S. titanus.

\section{Materials and methods}

\section{Study area and design}

The study area includes the whole vineyard area of Canton Ticino and covers 1093 ha (Fig. 1, Sezione dell'agricoltura Cantone Ticino 2019a). Since the detection of the quarantine disease "Flavescence dorée" in 2004 (Linder and Jermini 2007; Schaerer et al. 2007), two different control strategies have been applied. In the first phase (2004-2018), an eradication approach was implemented

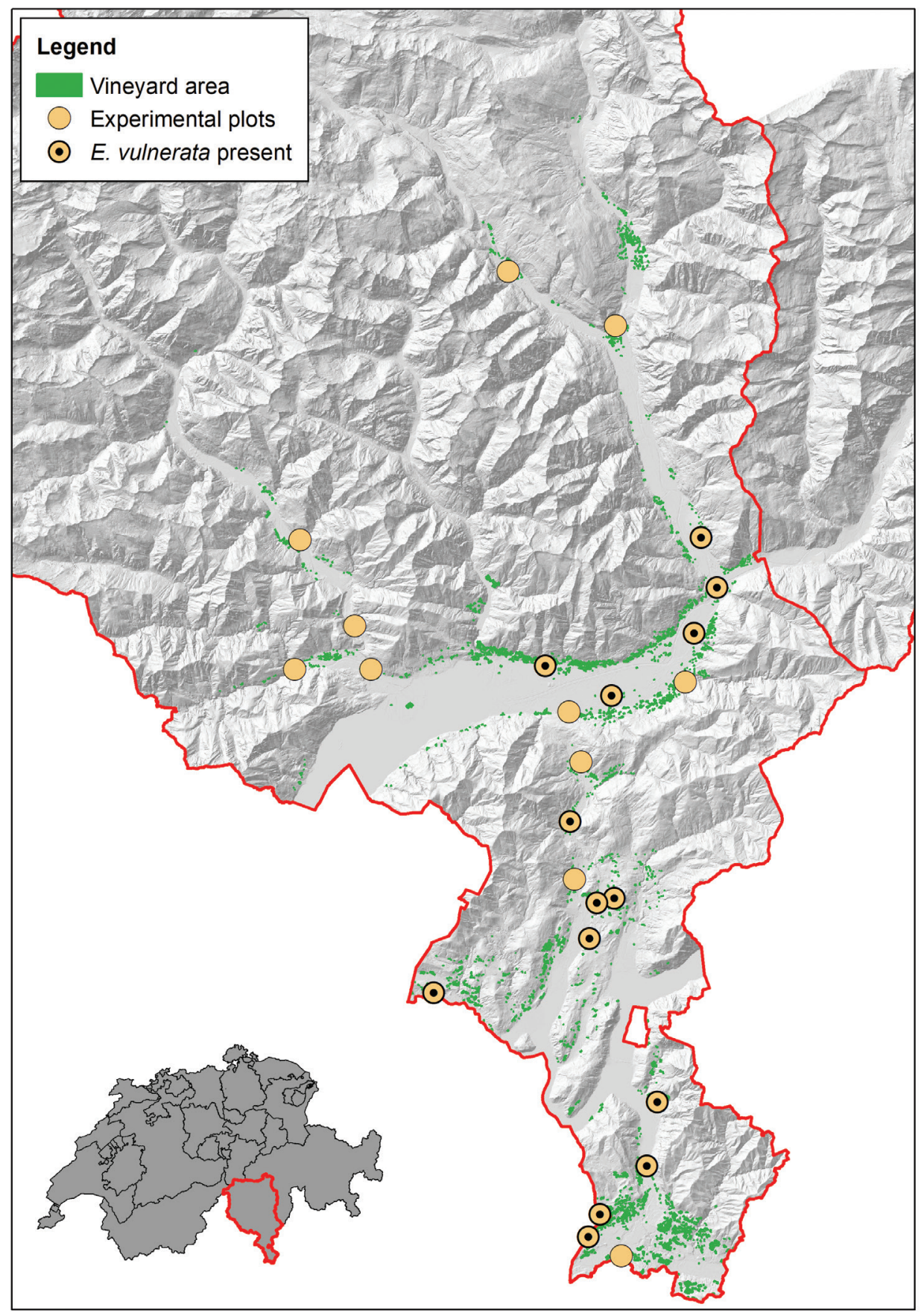

Figure 1. Study area and monitoring design. Green area: vineyard area in Canton Ticino; circles: experimental plots; black dots: Erasmoneura vulnerata presence. 
in the affected area consisting of the mandatory removal of symptomatic grapevines and the systematic insecticide application to control the phytoplasma vector S. titanus. Due to the widespread "Flavescence dorée" diffusion in the area (Jermini et al. 2014), cantonal authorities switched to an adaptive management approach in 2019 , consisting of the systematic removal of symptomatic grapevines (as before) and the application of insecticide treatments based on S. titanus population growth in the vineyards. Consequently, a temporary suspension of insecticide treatments and the implementation of a monitoring program on the reconstitution of $S$. titanus populations are in place for the period 2019-2020 (Sezione dell'agricoltura Cantone Ticino 2019b).

For the 2019 monitoring program, 28 vineyards distributed throughout the vineyard area of Canton Ticino were selected (Fig. 1) and provided with 6 to 15 yellow chromotropic sticky traps (Rebell, Giallo; Andermatt Biocontrol AG, Switzerland) based on vineyard size (183 traps in total, see Table 1).

\section{Collection and identification of specimens}

Traps were collected and changed every two weeks, from June 24 (week 26) to October 10 (week 41). Collected traps were then systematically checked for the presence of the main "Flavescence dorée" phytoplasma vector $S$. titanus and other alternative and putative vectors such as Orientus ishidae Matsumura, 1902 and Japananus hyalinus Osborn, 1900 (Lessio et al. 2016; Casati et al. 2017; Jermini et al. 2017). In this context, other particular or unknown species were also checked anecdotally. This was the case for $E$. vulnerata, which was identified following the description of Dmitriev et al. (2020). After the first instance of a presumed $E$. vulnerata specimen, details of leaf lesions and the presence of E. vulnerata excrement were additionally checked in the field following the observations of Paxton and Thorvilson (1996) (Fig. 2). Finally, selected males of the presumed E. vulnerata specimens were subjected to genitalia extraction to confirm the species according to Dmitriev et al. (2020).

\section{Results}

Specimens of E. vulnerata were found in 16 out of the 28 monitored plots as reported in Table 1. Currently, E. vulnerata is only present in the southern and central parts of Canton Ticino (Fig. 1). Unfortunately, no systematic and comprehensive counting of $E$. vulnerata specimens could be achieved because most of the collected traps had been processed and discarded before the first detection and confirmation of E. vulnerata.

Table 1. Experimental plots and occurrence of Erasmoneura vulnerata.

\begin{tabular}{|c|c|c|c|c|c|c|c|}
\hline Locality & Cultivar & Area $\left[\mathrm{m}^{2}\right]$ & YST $^{\mathrm{a}}$ & Latitude $^{\mathrm{b}}$ & Longitude $^{\mathrm{b}}$ & Elevation [m a.s.l.] & $\begin{array}{c}E \text {. vulnerata } \\
\text { presence }\end{array}$ \\
\hline Arbedo & Gamaret & 5336 & 6 & 46.21751 & 9.04110 & 238 & Yes \\
\hline Arzo & Chardonnay & 3084 & 6 & 45.86803 & 8.93728 & 480 & Yes \\
\hline Avegno & Chardonnay & 2256 & 6 & 46.19971 & 8.74874 & 281 & No \\
\hline Avegno & Merlot & 3726 & 9 & 46.19970 & 8.74759 & 282 & No \\
\hline Bedano & Merlot & 1925 & 6 & 46.05601 & 8.92144 & 394 & No \\
\hline Bellinzona & Merlot & 2418 & 6 & 46.19212 & 9.02190 & 260 & Yes \\
\hline Biasca & Merlot & 8340 & 6 & 46.36507 & 8.96342 & 310 & No \\
\hline Bironico & Gamaret & 4967 & 6 & 46.12143 & 8.92886 & 488 & No \\
\hline Cadenazzo & Merlot & 1024 & 6 & 46.15828 & 8.95441 & 206 & Yes \\
\hline Camorino & Merlot & 2138 & 6 & 46.16495 & 9.01409 & 372 & No \\
\hline Claro & Merlot & 9286 & 6 & 46.24579 & 9.02922 & 255 & Yes \\
\hline Contone & Gamaret & 11609 & 6 & 46.14920 & 8.92002 & 203 & No \\
\hline Genestrerio & Gamaret & 1566 & 6 & 45.84458 & 8.95361 & 376 & No \\
\hline Gerra Piano & Chardonnay \& Merlot & 10399 & 6 & 46.17559 & 8.90142 & 198 & Yes \\
\hline Giornico & Merlot & 6039 & 6 & 46.39669 & 8.87737 & 376 & No \\
\hline Intragna & Merlot & 1718 & 6 & 46.17601 & 8.69943 & 330 & No \\
\hline Lamone & Merlot & 10510 & 6 & 46.04243 & 8.93926 & 436 & Yes \\
\hline Losone & Chardonnay & 6487 & 6 & 46.17545 & 8.76098 & 223 & No \\
\hline Maggia & Merlot & 2165 & 6 & 46.24838 & 8.70566 & 336 & No \\
\hline Mendrisio & Cabernet Franc & 3514 & 6 & 45.89456 & 8.97548 & 300 & Yes \\
\hline Mezzovico & Merlot & 2981 & 6 & 46.08825 & 8.91926 & 413 & Yes \\
\hline Monteggio & Merlot & 7670 & 6 & 45.99369 & 8.80679 & 380 & Yes \\
\hline Origlio & Chardonnay \& Sauvignon Blanc & 13394 & 15 & 46.04369 & 8.94177 & 430 & Yes \\
\hline Rovio & Merlot & 2631 & 6 & 45.93004 & 8.98493 & 450 & Yes \\
\hline Stabio & Merlot & 1066 & 6 & 45.85767 & 8.93077 & 420 & Yes \\
\hline Stabio & Chardonnay & 3224 & 9 & 45.85563 & 8.92752 & 420 & Yes \\
\hline Stabio & Chardonnay & 1724 & 6 & 45.85456 & 8.92869 & 430 & Yes \\
\hline Vezia & Merlot & 4169 & 6 & 46.02249 & 8.93285 & 325 & Yes \\
\hline
\end{tabular}

${ }^{a}$ Number of yellow sticky traps inside vineyards (YST).

${ }^{\mathrm{b}}$ Coordinates in decimal degrees WGS 84 (N, E). 

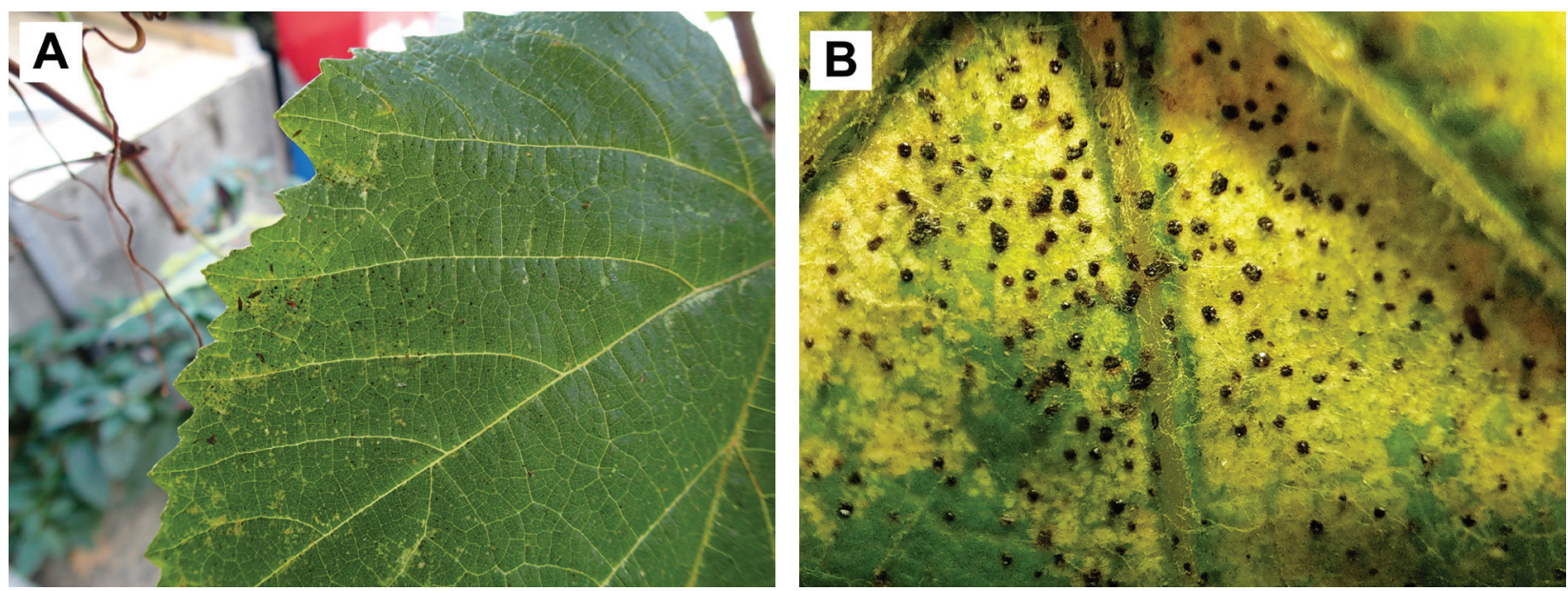

Figure 2. Foliage lesions and Erasmoneura vulnerata excrement. A Leaf lesions, excrement and specimens of $E$. vulnerata. B Details of leaf lesions and excrement left by E. vulnerata. Photographs taken in Bellinzona, Switzerland, 46.19212 N, 9.02190 E, 15 July 2019.
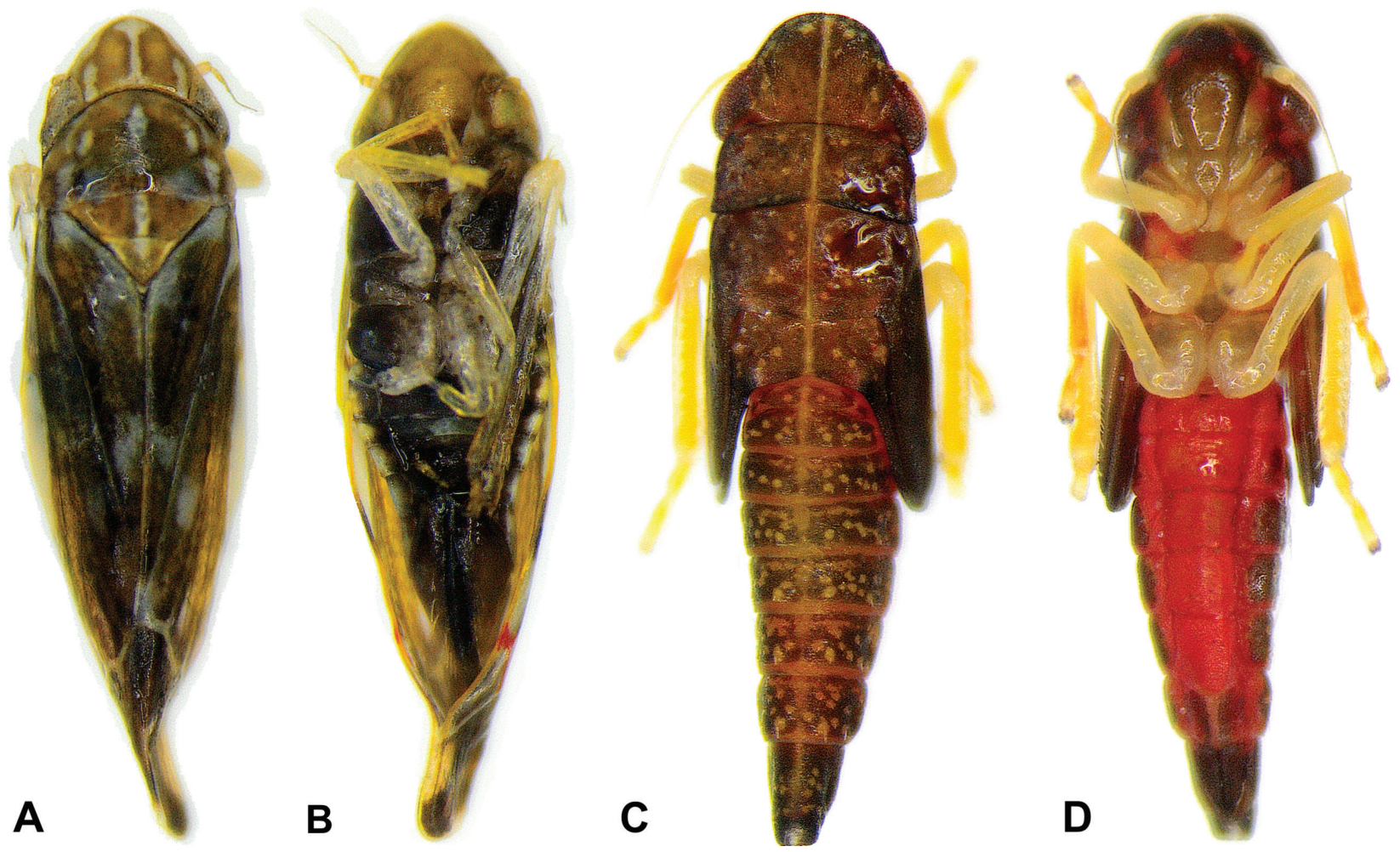

Figure 3. Erasmoneura vulnerata. Dorsal (A) and ventral (B) view of imago. Dorsal (C) and ventral (D) view of nymph. The real proportions were not retained.

\section{Biology of E. vulnerata}

\section{Description}

Adults of E. vulnerata are $2.7-3.2 \mathrm{~mm}$ long and are particularly identifiable by the characteristic transversal red veins at the base of the first apical cell on the forewings (Figs 3A, B; 4). Nymphs are reddish-brown with unordered yellowish marbled patches. The whole body is lon- gitudinally divided by a yellowish stripe (Fig. 3C, D). See Dmitriev et al. (2020) for further details on the species' morphology.

\section{Life cycle}

E. vulnerata reproduction takes place on Vitis spp. where it produces at least two generations per year with the possibility of a third under particularly favorable 


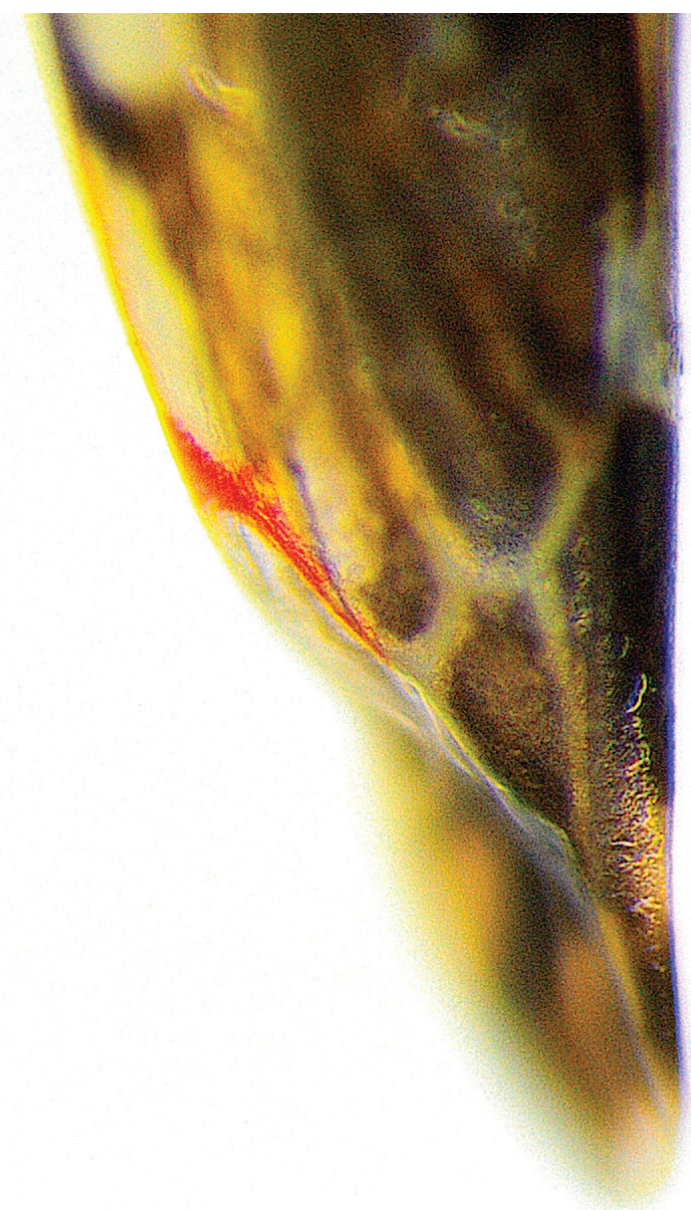

Figure 4. Detailed view of transversal red vein on forewing wing of Erasmoneura vulnerata.

conditions (Girolami et al. 2006). Adults begin colonizing grapevines at bud burst, moving from neighboring woody overwintering sites, the proximity of which to vineyards appears to be crucial for the establishment of E. vulnerata populations (Duso et al. 2019). Egg laying occurs in the tissue of larger leaf veins and the leaf midrib in particular. Egg laying peaks in June and August for the first and second generations, respectively (Duso et al. 2019). After hatching, both nymphal instars and adults mainly inhabit upper leaf surfaces, whereas exuviae are mainly observed on leaf undersides (Duso et al. 2005).

\section{Host plants and damage}

Vitis spp. is E. vulnerata's most suitable host plant (Dmitriev et al. 2020). In Europe, Vitis labrusca and Vitis vinifera are both colonized (Duso et al. 2019). However, Dmitriev et al. (2020) list many other host plant species in their database, including Parthenocissus quinquefolia, Ilex decidua Walter, and Aesculus spp. To date in Europe, the only species other than Vitis vinifera, Vitis labrusca, and Parthenocissus spp. that E. vulnerata has been found on is Cercis siliquastrum in Slovenia (Seljak 2011).
E. vulnerata is a mesophyll-feeding leafhopper. Leaf damage is recognizable as speckled whitish lesions, similar to those caused by the autochthonous Zygina rhamni Ferrari, 1882 (Seljak 2011). The presence of leaf lesions together with excrement left by E. vulnerata help differentiate damage caused by the two leafhopper species (Fig. 2; Paxton and Thorvilson 1996).

\section{Discussion}

The application of insecticides is the most important means of controlling leafhopper populations in vineyards (Duso et al. 2019). The ongoing temporary suspension of insecticide applications against $S$. titanus in Ticino has most likely permitted a general increase in leafhopper populations on grapevines, making the first occurrence of E. vulnerata in Switzerland in the frame of the current $S$. titanus monitoring program possible. This facilitation effect was already indirectly described by Duso et al. (2008), whose reports of E. vulnerata in Northeastern Italy refer to untreated Vitis labrusca and French hybrids.

The current spatial distribution of $E$. vulnerata in the study area suggests that this species had already been present for several years, and that the colonization most likely began from the southernmost part of Canton Ticino (Fig. 1), as already observed for Phyllocnistis vitegenella Clemens, 1859 (Cara and Jermini 2011; Cara et al. 2013). There is, however, no evidence to establish whether the arrival of E. vulnerata in Ticino is an example of accidental introduction or active migration from neighboring Italian vineyards, as proposed by Seljak (2011) for Slovenia.

E. vulnerata joins the three main vineyard leafhoppers that carry out part or their life cycle in the vineyards of Canton Ticino, namely Scaphoideus titanus, Zygina rhamni, and Empoasca vitis Goethe, 1875 (Viggiani 2002; Chuche and Thiéry 2014; Trivellone et al. 2016). While it is quite certain that the adaptive management approach currently being applied in Canton Ticino has permitted the reconstitution of leafhopper populations in vineyards, none of the aforementioned species currently poses a threat to grapevines in Southern Switzerland. In any case, the monitoring campaign in 2020 will allow for a better definition of the biology of E. vulnerata in the study area, determining, for example, the start of its colonization of grapevines and the number of generations since its introduction to Ticino.

\section{Acknowledgements}

The authors declare there are no conflicts of interest and have no funding to report.

We thank Dr. Valeria Trivellone for confirming the determination of the reported species through male genitalia inspection. 


\section{References}

Beamer R (1946) The Erythroneura of the vulnerata group (Homoptera-Cicadellidae). Journal of the Kansas Entomological Society 19: $15-22$.

Cara C, Jermini M (2011) La mineuse américaine Phyllocnistis vitegenella, un nouveau ravageur de la vigne au Tessin. Revue Suisse de Viticulture Arboriculture Horticulture 43(4): 224-230.

Cara C, Milani L, Trivellone V, Moretti M, Pezzatti G, Jermini M (2013) La minatrice americana (Phyllocnistis vitegenella): dinamica delle popolazioni e potenziale di biocontrollo naturale in Ticino (Svizzera). Bollettino della Società Ticinese di Scienze Naturali 101: 75-80.

Casati P, Jermini M, Quaglino F, Corbani G, Schaerer S, Passera A, et al. (2017) New insights on Flavescence dorée phytoplasma ecology in the vineyard agro-ecosystem in southern Switzerland. Annals of Applied Biology 171: 37-51. https://doi.org/10.1111/aab.12359

Chuche J, Thiéry D (2014) Biology and ecology of the Flavescence dorée vector Scaphoideus titanus: A review. Agronomy for Sustainable Development 34(2): 381-403. https://doi.org/10.1007/s13593014-0208-7

Dietrich CH, Dmitriev DA (2006) Review of the New World genera of the leafhopper tribe Erythroneurini (Hemiptera: Cicadellidae: Typhlocybinae). Illinois Natural History Survey Bulletin 37(5): 119-190. https://doi.org/10.21900/j.inhs.v37.121

Dmitriev DA, Sanborn A, Takiya D (2020) 3i Auchenorrhyncha: World Auchenorrhyncha Database (version Nov 2017). In: Roskov Y, Ower G, Orrell T, Nicolson D, Bailly N, Kirk PM, Bourgoin T, DeWalt RE, Decock W, van Nieukerken E, Penev L (Eds) Species 2000 \& ITIS Catalogue of Life, 2020-02-24. Leiden, The Netherlands, www.catalogueoflife.org/col. [ISSN 2405-8858]

Duso C, Bressan A, Mazzon L, Girolami V (2005) First record of the grape leafhopper Erythroneura vulnerata Fitch (Hom., Cicadellidae) in Europe. Journal of Applied Entomology 129(3): 170-172. https://doi.org/10.1111/j.1439-0418.2005.00944.x

Duso C, Moret R, Marchegiani G, Pozzebon A (2008) Notes on the distribution and the phenology of Erasmoneura vulnerata (Fitch) (Homoptera: Cicadellidae) in North-eastern Italy. IOBC/WPRS Bulletin 36: $251-254$.

Duso C, Moret R, Manera A, Berto D, Fornasiero D, Marchegiani G, et al. (2019) Investigations on the grape leafhopper Erasmoneura vulnerata in North-eastern Italy. Insects 10(2): https://doi.org/10.3390/ insects 10020044

Girolami V, Duso C, Mazzon L, Bressan A (2006) Nuova cicalina della vite in Italia. L'Informatore Agrario 24: 65-67.

Jermini M, Schaerer S, Johnston H, Colombi L, Marazzi C, Schaerer S, et al. (2014) Dix ans de flavescence dorée au Tessin. Revue Suisse de Viticulture Arboriculture Horticulture 46(4): 222-229.

Jermini M, Schaerer S, Casati P, Corbani G, Quaglino F, Rigamonti IE, et al. (2017) Orientus ishidae, un nouveau vecteur de la flavescence dorée au Tessin. Revue Suisse de Viticulture Arboriculture Horticulture 49(5): 208-288.

Lessio F, Picciau L, Gonella E, Mandrioli M, Tota F, Alma A (2016) The mosaic leafhopper Orientus ishidae: Host plants, spatial distribution, infectivity, and transmission of $16 \mathrm{SrV}$ phytoplasmas to vines. Bulletin of Insectology 69(2): 277-289.

Linder C, Jermini M (2007) Biologie et distribution du vecteur de la flavescence dorée dans les vignobles. Revue Suisse de Viticulture Arboriculture Horticulture 39(2): 97-101.

Martinson TE, Dennehy TJ (1995) Varietal preferences of Erythroneura leafhoppers (Homoptera: Cicadellidae) feeding on grapes in New York. Environmental Entomology. Entomological Society of America 24(3): 550-558. https://doi.org/10.1093/ee/24.3.550

Mühlethaler R, Trivellone V, van Klink R, Niedringhaus R, Nickel H (2016) Kritische Artenliste der Zikaden der Schweiz (Hemiptera: Auchenorrhyncha). Cicadina 16: 49-87.

OSalV-DEFR-DATEC (2019) Ordinanza del DEFR e del DATEC concernente l'ordinanza sulla salute dei vegetali del 14 novembre 2019 (RU 2019 4773). Legislative decision. https://www.admin.ch/opc/it/classified-compilation/20192243/index.html [Accessed on 01.04.2020]

Paxton D, Thorvilson H (1996) Oviposition of three Erythroneura species on grape leaves in Western Texas. Southwestern Entomologist 21(2): 141-144.

Robinson W (1926) The genus Erythroneura north of Mexico (Homoptera, Cicadellidae). Science Bulletin of the University of Kansas 16(3): 101-155. https://doi.org/10.5962/bhl.part.7264

Schaerer S, Johnston H, Gugerli P (2007) Flavescence dorée: la maladie et son extension. Revue Suisse de Viticulture Arboriculture Horticulture 39(2): 107-110.

Seljak G (2011) First record of the Nearctic leafhopper Erasmoneura vulnerata (Fitch, 1851) [Hemiptera, Cicadomorpha: Cicadellidae] in Slovenia. Acta Entomologica Slovenica 19(1): 37-42.

Sezione dell'agricoltura Cantone Ticino (2019a) Rapporto sulla vendemmia 2018. Bellinzona (Switzerland). https://m4.ti.ch/fileadmin/ DFE/DE-SA/comunicati/annatevitic/rapporto_vendem mia_2018_ cantone.pdf [Accessed on 20.03.2020]

Sezione dell'agricoltura Cantone Ticino (2019b) Strategie di contenimento e monitoraggio della flavescenza dorata della vite e dell'insetto vettore Scaphoideus titanus, Ball. Legislative decision. Foglio Ufficiale Repubblica e Cantone Ticino, N. 016/2019.

Trivellone V, Jermini M, Cara C (2016) Les cicadelles typhlocybines (Hemiptera: Cicadellidae) de la vigne et leurs parasitoïdes dans le vignoble tessinois. Revue Suisse de Viticulture Arboriculture Horticulture 48(6): 368-375.

Viggiani G (2002) Egg parasitoids of vineyard leafhoppers and their alternative hosts in the Mediterranean Basin. Bollettino del Laboratorio di Entomologia Agraria "Filippo Silvestri" Portici 58: 63-76.

Zimmerman R, Kondratieff B, Nelson E, Sclar C (1996) The life history of two species of grape leafhoppers on wine grapes in Western Colorado. Journal of the Kansas Entomological Society 69(4): 337-345. 